\title{
Strong Convergence Theorems for Nonexpansive Semigroups without Bochner Integrals
}

\author{
Satit Saejung \\ Department of Mathematics, Faculty of Science, Khon Kaen University, Khon Kaen 40002, Thailand
}

Correspondence should be addressed to Satit Saejung, saejung@kku.ac.th

Received 28 November 2007; Revised 15 January 2008; Accepted 30 January 2008

Recommended by William A. Kirk

We prove a convergence theorem by the new iterative method introduced by Takahashi et al. (2007). Our result does not use Bochner integrals so it is different from that by Takahashi et al. We also correct the strong convergence theorem recently proved by He and Chen (2007).

Copyright (C) 2008 Satit Saejung. This is an open access article distributed under the Creative Commons Attribution License, which permits unrestricted use, distribution, and reproduction in any medium, provided the original work is properly cited.

\section{Introduction}

Let $H$ be a real Hilbert space with the inner product $\langle\cdot, \cdot\rangle$ and the norm $\|\cdot\|$. Let $\{T(t): t \geq 0\}$ be a family of mappings from a subset $C$ of $H$ into itself. We call it a nonexpansive semigroup on $C$ if the following conditions are satisfied:

(1) $T(0) x=x$ for all $x \in C$;

(2) $T(s+t)=T(s) T(t)$ for all $s, t \geq 0$;

(3) for each $x \in C$ the mapping $t \mapsto T(t) x$ is continuous;

(4) $\|T(t) x-T(t) y\| \leq\|x-y\|$ for all $x, y \in C$ and $t \geq 0$.

Motivated by Suzuki's result [1] and Nakajo-Takahashi's results [2], He and Chen [3] recently proved a strong convergence theorem for nonexpansive semigroups in Hilbert spaces by hybrid method in the mathematical programming. However, their proof of the main result ([3, Theorem 2.3]) is very questionable. Indeed, the existence of the subsequence $\left\{s_{j}\right\}$ such that (2.16) of [3] are satisfied, that is,

$$
s_{j} \longrightarrow 0, \quad \frac{\left\|x_{j}-T\left(s_{j}\right) x_{j}\right\|}{s_{j}} \longrightarrow 0,
$$

needs to be proved precisely. So, the aim of this short paper is to correct He-Chen's result and also to give a new result by using the method recently introduced by Takahashi et al. 
We need the following lemma proved by Suzuki [4, Lemma 1].

Lemma 1.1. Let $\left\{t_{n}\right\}$ be a real sequence and let $\tau$ be a real number such that $\liminf _{n} t_{n} \leq \tau \leq$ $\lim \sup _{n} t_{n}$. Suppose that either of the following holds:

(i) $\lim \sup _{n}\left(t_{n+1}-t_{n}\right) \leq 0$, or

(ii) $\liminf \operatorname{in}_{n}\left(t_{n+1}-t_{n}\right) \geq 0$.

Then $\tau$ is a cluster point of $\left\{t_{n}\right\}$. Moreover, for $\varepsilon>0, k, m \in \mathbb{N}$, there exists $m_{0} \geq m$ such that $\left|t_{j}-\tau\right|<\varepsilon$ for every integer $j$ with $m_{0} \leq j \leq m_{0}+k$.

\section{Results}

\subsection{The shrinking projection method}

The following method is introduced by Takahashi et al. in [5]. We use this method to approximate a common fixed point of a nonexpansive semigroup without Bochner integrals as was the case in [5, Theorem 4.4].

Theorem 2.1. Let $C$ be a closed convex subset of a real Hilbert space $H$. Let $\{T(t): t \geq 0\}$ be a nonexpansive semigroup on $C$ with a nonempty common fixed point $F$, that is, $F=\cap_{t \geq 0} F(T(t)) \neq \varnothing$. Suppose that $\left\{x_{n}\right\}$ is a sequence iteratively generated by the following scheme:

$$
\begin{gathered}
x_{0} \in H \text { taken arbitrary, } \\
C_{1}=C, \\
x_{1}=P_{C_{1}}\left(x_{0}\right), \\
y_{n}=\alpha_{n} x_{n}+\left(1-\alpha_{n}\right) T\left(t_{n}\right) x_{n}, \\
C_{n+1}=\left\{z \in C_{n}:\left\|y_{n}-z\right\| \leq\left\|x_{n}-z\right\|\right\}, \\
x_{n+1}=P_{C_{n+1}}\left(x_{0}\right) .
\end{gathered}
$$

where $\left\{\alpha_{n}\right\} \subset[0, a] \subset[0,1), \liminf _{n} t_{n}=0, \limsup _{n} t_{n}>0$, and $\lim _{n}\left(t_{n+1}-t_{n}\right)=0$. Then $x_{n} \rightarrow$ $P_{F}\left(x_{0}\right)$.

Proof. It is well known that $F$ is closed and convex. We first show that the iterative scheme is well defined. To see that each $C_{n}$ is nonempty, it suffices to show that $F \subset C_{n}$. The proof is by induction. Clearly, $F \subset C_{1}$. Suppose that $F \subset C_{k}$. Then, for $z \in F \subset C_{k}$,

$$
\begin{aligned}
\left\|y_{k}-z\right\| & \leq \alpha_{k}\left\|x_{k}-z\right\|+\left(1-\alpha_{k}\right)\left\|T\left(t_{k}\right) x_{k}-z\right\| \\
& \leq \alpha_{k}\left\|x_{k}-z\right\|+\left(1-\alpha_{k}\right)\left\|x_{k}-z\right\| \\
& =\left\|x_{k}-z\right\| .
\end{aligned}
$$

That is, $z \in C_{k+1}$ as required.

Notice that

$$
\widehat{C}_{n}:=\left\{z \in H:\left\|y_{n}-z\right\| \leq\left\|x_{n}-z\right\|\right\}
$$


is convex since

$$
\left\|y_{n}-z\right\| \leq\left\|x_{n}-z\right\| \Longleftrightarrow 2\left\langle x_{n}-y_{n}, z\right\rangle \leq\left\|x_{n}\right\|^{2}-\left\|y_{n}\right\|^{2}
$$

This implies that each subset $C_{n}=C \cap \widehat{C}_{1} \cap \cdots \cap \widehat{C}_{n-1}$ is convex. It is also clear that $C_{n}$ is closed. Hence the first claim is proved.

Next, we prove that $\left\{x_{n}\right\}$ is bounded. As $x_{n}=P_{C_{n}}\left(x_{0}\right)$,

$$
\left\|x_{n}-x_{0}\right\| \leq\left\|z-x_{0}\right\| \quad \forall z \in C_{n}
$$

In particular, for $z \in F \subset C_{n}$ for all $n \in \mathbb{N}$, the sequence $\left\{x_{n}-x_{0}\right\}$ is bounded and hence so is $\left\{x_{n}\right\}$.

Next, we show that $\left\{x_{n}\right\}$ is a Cauchy sequence. As $x_{n+1} \in C_{n+1} \subset C_{n}$ and $x_{n}=P_{C_{n}}\left(x_{0}\right)$,

$$
\left\|x_{n}-x_{0}\right\| \leq\left\|x_{n+1}-x_{0}\right\| \quad \forall n
$$

Moreover, since the sequence $\left\{x_{n}\right\}$ is bounded,

$$
\lim _{n \rightarrow \infty}\left\|x_{n}-x_{0}\right\| \text { exists. }
$$

Note that

$$
\left\langle x_{0}-x_{n}, x_{n}-v\right\rangle \geq 0 \quad \forall v \in C_{n}
$$

In particular, since $x_{n+k} \in C_{n+k} \subset C_{n}$ for all $k \in \mathbb{N}$,

$$
\begin{aligned}
\left\|x_{n+k}-x_{n}\right\|^{2} & =\left\|x_{n+k}-x_{0}\right\|^{2}-\left\|x_{n}-x_{0}\right\|^{2}-2\left\langle x_{n+k}-x_{n}, x_{n}-x_{0}\right\rangle \\
& \leq\left\|x_{n+k}-x_{0}\right\|^{2}-\left\|x_{n}-x_{0}\right\|^{2} .
\end{aligned}
$$

It then follows from the existence of $\lim _{n}\left\|x_{n}-x_{0}\right\|^{2}$ that $\left\{x_{n}\right\}$ is a Cauchy sequence. In fact, for $\varepsilon>0$, there exists a natural number $N$ such that, for all $n \geq N$,

$$
\left|\left\|x_{n}-x_{0}\right\|^{2}-a\right|<\frac{\varepsilon}{2}
$$

where $a=\lim _{n}\left\|x_{n}-x_{0}\right\|^{2}$. In particular, if $n \geq N$ and $k \in \mathbb{N}$, then

$$
\begin{aligned}
\left\|x_{n+k}-x_{n}\right\|^{2} & \leq\left\|x_{n+k}-x_{0}\right\|^{2}-\left\|x_{n}-x_{0}\right\|^{2} \\
& \leq a+\frac{\varepsilon}{2}-\left(a-\frac{\varepsilon}{2}\right)=\varepsilon
\end{aligned}
$$

Moreover,

$$
\left\|x_{n+1}-x_{n}\right\| \longrightarrow 0
$$


We now assume that $x_{n} \rightarrow p$ for some $p \in C$. Now since $\alpha_{n} \leq a<1$ for all $n \in \mathbb{N}$ and $x_{n+1} \in C_{n}$,

$$
\begin{aligned}
\left\|x_{n}-T\left(t_{n}\right) x_{n}\right\| & =\frac{1}{1-\alpha_{n}}\left\|y_{n}-x_{n}\right\| \\
& \leq \frac{1}{1-a}\left(\left\|y_{n}-x_{n+1}\right\|+\left\|x_{n+1}-x_{n}\right\|\right) \\
& \leq \frac{2}{1-a}\left\|x_{n+1}-x_{n}\right\| \longrightarrow 0 .
\end{aligned}
$$

The last convergence follows from (2.12). We choose a sequence $\left\{t_{n_{k}}\right\}$ of positive real number such that

$$
t_{n_{k}} \longrightarrow 0, \quad \frac{1}{t_{n_{k}}}\left\|x_{n_{k}}-T\left(t_{n_{k}}\right) x_{n_{k}}\right\| \longrightarrow 0
$$

We now show that how such a special subsequence can be constructed. First we fix $\delta>0$ such that

$$
\liminf _{n} t_{n}=0<\delta<\limsup _{n} t_{n}
$$

From (2.13), there exists $m_{1} \in \mathbb{N}$ such that $\left\|T\left(t_{n}\right) x_{n}-x_{n}\right\|<1 / 3^{2}$ for all $n \geq m_{1}$. By Lemma 1.1, $\delta / 2$ is a cluster point of $\left\{t_{n}\right\}$. In particular, there exists $n_{1}>m_{1}$ such that $\delta / 3<t_{n_{1}}<\delta$. Next, we choose $m_{2}>n_{1}$ such that $\left\|T\left(t_{n}\right) x_{n}-x_{n}\right\|<1 / 4^{2}$ for all $n \geq m_{2}$. Again, by Lemma $1.1, \delta / 3$ is a cluster point of $\left\{t_{n}\right\}$ and this implies that there exists $n_{2}>m_{2}$ such that $\delta / 4<t_{n_{2}}<\delta / 2$. Continuing in this way, we obtain a subsequence $\left\{n_{k}\right\}$ of $\{n\}$ satisfying

$$
\left\|T\left(t_{n_{k}}\right) x_{n_{k}}-x_{n_{k}}\right\|<\frac{1}{(k+2)^{2}}, \quad \frac{\delta}{k+2}<t_{n_{k}}<\frac{\delta}{k} \quad \forall k \in \mathbb{N} .
$$

Consequently, (2.14) is satisfied.

We next show that $p \in F$. To see this, we fix $t>0$,

$$
\begin{aligned}
& \left\|x_{n_{k}}-T(t) p\right\| \\
& \leq \sum_{j=0}^{\left[t / t_{n_{k}}\right]-1}\left\|T\left(j t_{n_{k}}\right) x_{n_{k}}-T\left((j+1) t_{n_{k}}\right) x_{n_{k}}\right\| \\
& \quad+\left\|T\left(\left[\frac{t}{t_{n_{k}}}\right] t_{n_{k}}\right) x_{n_{k}}-T\left(\left[\frac{t}{t_{n_{k}}}\right] t_{n_{k}}\right) p\right\|+\left\|T\left(\left[\frac{t}{t_{n_{k}}}\right] t_{n_{k}}\right) p-T(t) p\right\| \\
& \leq\left[\frac{t}{t_{n_{k}}}\right]\left\|x_{n_{k}}-T\left(t_{n_{k}}\right) x_{n_{k}}\right\|+\left\|x_{n_{k}}-p\right\|+\left\|T\left(t-\left[\frac{t}{t_{n_{k}}}\right] t_{n_{k}}\right) p-p\right\| \\
& \leq \frac{t}{t_{n_{k}}}\left\|x_{n_{k}}-T\left(t_{n_{k}}\right) x_{n_{k}}\right\|+\left\|x_{n_{k}}-p\right\|+\sup \left\{\|T(s) p-p\|: 0 \leq s \leq t_{n_{k}}\right\} .
\end{aligned}
$$

As $x_{n_{k}} \rightarrow p$ and (2.14), we have $x_{n_{k}} \rightarrow T(t) p$ and so $T(t) p=p$.

Finally, we show that $p=P_{F}\left(x_{0}\right)$. Since $F \subset C_{n+1}$ and $x_{n+1}=P_{C_{n+1}}\left(x_{0}\right)$,

$$
\left\|x_{n+1}-x_{0}\right\| \leq\left\|q-x_{0}\right\| \quad \forall n \in \mathbb{N}, q \in F .
$$


But $x_{n} \rightarrow p$; we have

$$
\left\|p-x_{0}\right\| \leq\left\|q-x_{0}\right\| \quad \forall q \in F .
$$

Hence $p=P_{F}\left(x_{0}\right)$ as required. This completes the proof.

\subsection{The hybrid method}

We consider the iterative scheme computing by the hybrid method (some authors call the CQmethod). The following result is proved by He and Chen [3]. However, the important part of the proof seems to be overlooked. Here we present the correction under some additional restriction on the parameter $\left\{t_{n}\right\}$.

Theorem 2.2. Let $C$ be a closed convex subset of a real Hilbert space $H$. Let $\{T(t): t \geq 0\}$ be a nonexpansive semigroup on $C$ with a nonempty common fixed point $F$, that is, $F=\cap_{t \geq 0} F(T(t)) \neq \varnothing$. Suppose that $\left\{x_{n}\right\}$ is a sequence iteratively generated by the following scheme:

$$
\begin{gathered}
x_{0} \in C \text { taken arbitrary, } \\
y_{n}=\alpha_{n} x_{n}+\left(1-\alpha_{n}\right) T\left(t_{n}\right) x_{n}, \\
C_{n}=\left\{z \in C:\left\|y_{n}-z\right\| \leq\left\|x_{n}-z\right\|\right\}, \\
Q_{n}=\left\{z \in C:\left\langle x_{n}-x_{0}, z-x_{n}\right\rangle \geq 0\right\}, \\
x_{n+1}=P_{C_{n} \cap Q_{n}}\left(x_{0}\right),
\end{gathered}
$$

where $\left\{\alpha_{n}\right\} \subset[0, a] \subset[0,1), \liminf _{n} t_{n}=0, \limsup _{n} t_{n}>0$, and $\lim _{n}\left(t_{n+1}-t_{n}\right)=0$. Then $x_{n} \rightarrow$ $P_{F}\left(x_{0}\right)$.

Proof. For the sake of clarity, we give the whole sketch proof even though some parts of the proof are the same as [3]. To see that the scheme is well defined, it suffices to show that both $C_{n}$ and $Q_{n}$ are closed and convex, and $C_{n} \cap Q_{n} \neq \varnothing$ for all $n \in \mathbb{N}$. It follows easily from the definition that $C_{n}$ and $Q_{n}$ are just the intersection of $C$ and the half-spaces, respectively,

$$
\begin{aligned}
& \widehat{C}_{n}:=\left\{z \in H: 2\left\langle x_{n}-y_{n}, z\right\rangle \leq\left\|x_{n}\right\|^{2}-\left\|y_{n}\right\|^{2}\right\}, \\
& \widehat{Q}_{n}:=\left\{z \in H:\left\langle x_{n}-x_{0}, z-x_{n}\right\rangle \geq 0\right\} .
\end{aligned}
$$

As in the proof of the preceding theorem, we have $F \subset C_{n}$ for all $n \in \mathbb{N}$. Clearly, $F \subset C=Q_{1}$. Suppose that $F \subset Q_{k}$ for some $k \in \mathbb{N}$, we have $p \in C_{k} \cap Q_{k}$. In particular, $\left\langle x_{k+1}-x_{0}, p-x_{k+1}\right\rangle \geq 0$, that is, $p \in Q_{k+1}$. It follows from the induction that $F \subset Q_{n}$ for all $n \in \mathbb{N}$. This proves the claim.

We next show that $x_{n}-T\left(t_{n}\right) x_{n} \rightarrow 0$. To see this, we first prove that

$$
x_{n+1}-x_{n} \longrightarrow 0
$$

As $x_{n+1} \in Q_{n}$ and $x_{n}=P_{Q_{n}}\left(x_{0}\right)$,

$$
\left\|x_{n}-x_{0}\right\| \leq\left\|x_{n+1}-x_{0}\right\| \quad \forall n \in \mathbb{N}
$$


For fixed $z \in F$. It follows from $F \subset Q_{n}$ for all $n \in \mathbb{N}$ that

$$
\left\|x_{n}-x_{0}\right\| \leq\left\|z-x_{0}\right\| \quad \forall n \in \mathbb{N} .
$$

This implies that sequence $\left\{x_{n}\right\}$ is bounded and

$$
\lim _{n \rightarrow \infty}\left\|x_{n}-x_{0}\right\| \text { exists. }
$$

Notice that

$$
\left\langle x_{n+1}-x_{n}, x_{n}-x_{0}\right\rangle \geq 0
$$

This implies that

$$
\begin{aligned}
\left\|x_{n+1}-x_{n}\right\|^{2} & =\left\|x_{n+1}-x_{0}\right\|^{2}-\left\|x_{n}-x_{0}\right\|^{2}-2\left\langle x_{n+1}-x_{n}, x_{n}-x_{0}\right\rangle \\
& \leq\left\|x_{n+1}-x_{0}\right\|^{2}-\left\|x_{n}-x_{0}\right\|^{2} \longrightarrow 0 .
\end{aligned}
$$

It then follows from $x_{n+1} \in C_{n}$ that $\left\|y_{n}-x_{n+1}\right\| \leq\left\|x_{n}-x_{n+1}\right\|$ and hence

$$
\begin{aligned}
\left\|T\left(t_{n}\right) x_{n}-x_{n}\right\| & =\frac{1}{\alpha_{n}}\left\|y_{n}-x_{n}\right\| \\
& \leq \frac{1}{\alpha_{n}}\left(\left\|y_{n}-x_{n+1}\right\|+\left\|x_{n+1}-x_{n}\right\|\right) \longrightarrow 0 .
\end{aligned}
$$

As in Theorem 2.1, we can choose a subsequence $\left\{n_{k}\right\}$ of $\{n\}$ such that

$$
x_{n_{k}} \stackrel{w}{\longrightarrow} p \in C, t_{n_{k}} \longrightarrow 0, \frac{1}{t_{n_{k}}}\left\|x_{n_{k}}-T\left(t_{n_{k}}\right) x_{n_{k}}\right\| \longrightarrow 0 .
$$

Consequently, for any $t>0$,

$$
\left\|x_{n_{k}}-T(t) p\right\| \leq \frac{t}{t_{n_{k}}}\left\|x_{n_{k}}-T\left(t_{n_{k}}\right) x_{n_{k}}\right\|+\left\|x_{n_{k}}-p\right\|+\sup \left\{\|T(s) p-p\|: 0 \leq s \leq t_{n_{k}}\right\} .
$$

This implies that

$$
\limsup _{k \rightarrow \infty}\left\|x_{n_{k}}-T(t) p\right\| \leq \limsup _{k \rightarrow \infty}\left\|x_{n_{k}}-p\right\| .
$$

In virtue of Opial's condition of $H$, we have $p=T(t) p$ for all $t>0$, that is, $p \in F$. Next, we observe that

$$
\left\|x_{0}-P_{F}\left(x_{0}\right)\right\| \leq\left\|x_{0}-p\right\| \leq \liminf _{k \rightarrow \infty}\left\|x_{0}-x_{n_{k}}\right\| \leq \limsup _{k \rightarrow \infty}\left\|x_{0}-x_{n_{k}}\right\| \leq\left\|x_{0}-P_{F}\left(x_{0}\right)\right\| .
$$

This implies that

$$
\lim _{k \rightarrow \infty}\left\|x_{0}-x_{n_{k}}\right\|=\left\|x_{0}-P_{F}\left(x_{0}\right)\right\|=\left\|x_{0}-p\right\|
$$

Consequently,

$$
x_{n_{k}} \longrightarrow P_{F}\left(x_{0}\right)=p .
$$

Hence the whole sequence must converge to $P_{F}\left(x_{0}\right)=p$, as required. 


\section{Acknowledgments}

The author would like to thank the referee(s) for his comments and suggestions on the manuscript. This work is supported by the Commission on Higher Education and the Thailand Research Fund (Grant MRG4980022).

\section{References}

[1] T. Suzuki, "On strong convergence to common fixed points of nonexpansive semigroups in Hilbert spaces," Proceedings of the American Mathematical Society, vol. 131, no. 7, pp. 2133-2136, 2003.

[2] K. Nakajo and W. Takahashi, "Strong convergence theorems for nonexpansive mappings and nonexpansive semigroups," Journal of Mathematical Analysis and Applications, vol. 279, no. 2, pp. 372-379, 2003.

[3] H. He and R. Chen, "Strong convergence theorems of the CQ method for nonexpansive semigroups," Fixed Point Theory and Applications, vol. 2007, Article ID 59735, 8 pages, 2007.

[4] T. Suzuki, "Strong convergence of Krasnoselskii and Mann's type sequences for one-parameter nonexpansive semigroups without Bochner integrals," Journal of Mathematical Analysis and Applications, vol. 305, no. 1, pp. 227-239, 2005.

[5] W. Takahashi, Y. Takeuchi, and R. Kubota, "Strong convergence theorems by hybrid methods for families of nonexpansive mappings in Hilbert spaces," Journal of Mathematical Analysis and Applications, vol. 341, no. 1, pp. 276-286, 2007. 